\title{
Protein patterning by UV-induced photodegradation of poly(oligo(ethylene glycol) methacrylate) brushes
}

\begin{abstract}
The UV photodegradation of protein-resistant poly(oligo(ethylene glycol) methacrylate) (POEGMA) bottle-brush films, grown on silicon oxide by surface-initiated atom radical transfer polymerization, was studied using X-ray photoelectron spectroscopy (XPS) and atomic force microscopy (AFM). Exposure to light with a wavelength of $244 \mathrm{~nm}$ caused a loss of polyether units from the brush structure and the creation of aldehyde groups that could be derivatized with amines. An increase was measured in the coefficient of friction of the photodegraded polymer brush compared to the native brush, attributed to the creation of a heterogeneous surface film, leading to increased energy dissipation through film deformation and the creation of new polar functional groups at the surface. Exposure of the films through a photomask yielded sharp, well-defined patterns. Analysis of topographical images showed that physical removal of material occurred during exposure, at a rate of $1.35 \mathrm{~nm} \mathrm{~J}-1 \mathrm{~cm} 2$. Using fluorescence microscopy, the adsorption of labeled proteins onto the exposed surfaces was studied. It was found that protein strongly adsorbed to exposed areas, while the masked regions retained their protein resistance. Exposure of the film to UV light from a scanning near-field optical microscope yielded submicrometer-scale patterns. These data indicate that a simple, rapid, one-step photoconversion of the poly(OEGMA) brush occurs that transforms it from a highly protein-resistant material to one that adsorbs protein and can covalently bind amine-containing molecules and that this photoconversion can be spatially addressed with high spatial resolution.
\end{abstract}

Keyword: Protein Patterning; SNP; POEGMA; Prototypical protein resistant material 